\title{
A Necessary Inhumanity?
}

Ruth Richardson Historian, London

\begin{abstract}
It is argued that the phrase "Necessary Inhumanity" more accurately describes the alienation required of

doctors in some circumstances, than do modern sanitised coinages such as 'clinical detachment'. 'Detachment' and 'objectivity' imply separation, not engagement: creating distance not only from patients, but from the self: the process may well be required, but where it becomes too extreme or prolonged, it can damage everybody, including patients, family members, doctors themselves, and wider society. An awareness of the history of health care in the context of our society might assist self reflection-might help keep initiates in touch with the culture they have been induced to leave and might help them remain humane despite the bruising process of training.

( $($ Med Ethics: Medical Humanities 2000;26:104-106)
\end{abstract}

Keywords: Detachment; medical culture; remuneration; presumed consent; specimens; dissection

\section{Introduction}

The title of this paper is taken from the teaching of the eighteenth century surgeon-anatomist, William Hunter, who urged his students to gain "a Necessary Inhumanity" by dissecting the dead. Hunter knew that trainee doctors could not be too tender, that this inhumanity would stand his students in good stead in dealing with the surgery of the day, which - in the days before anaesthesia, antisepsis or transfusion-needed to be not just accurate but fast if it was to be successful.

Nowadays, we call this necessary inhumanity "clinical detachment" or something similar which sounds less emotive, more scientific. But in a sense Hunter's words are more honest. They help clarify what he was actually urging - inhumanity - but only to a necessary degree. The phrase has more precision, a suggestion of calibration, even a hint of warning, which clinical "detachment" and "objectivity" lack.

Whatever we call it, it clearly has value even today: it can be protective for both patient and doctor, allows each generation to learn how to examine, diagnose, treat, operate, and verify diagnoses after death. It's key, then. But there are also dangers. A doctor currently practising in the UK recollects:

"Dissecting earthworms in biology was no preparation. ... One of the students was unable to sit through the introductory lecture, which was about scalpels and forceps, and fat and fascia, because of the thought of dissecting. And the first week that we were in the dissecting room he spent throwing up in the loo. At the end of the first week he blew his brains out with a shotgun."

"... Dissecting [is] a strange way to be introduced to patients ... we start with a pickled patient. This curious introduction resulted in such misbehaviour as games of cricket played with human arms and large blood clots. Even shy and gentle me looked down one day to see that I was swinging a human head nonchalantly by its windpipe."

This passage conveys a painful understanding of the impact of conventional medical training. This doctor is still haunted by it. He reveals the astonishment he felt when he realised that against all the odds, he had somehow acquired a detachment which apparently extended to his own arm. This doctor suffered a sort of existential unease at what he'd been forced to undergo, and took a conscious decision to deal with it at an early stage:

"I found myself looking at the body as a wonderful machine, but not as a creature with a soul - that worried me a bit. What in fact I had to do was consciously unlearn that sort of thing, and start to look at human beings as human beings." (Personal communication: my informant currently wishes to remain anonymous.)

$\mathrm{He}$ speaks very simply, and I think rather downplays the importance of what he's saying, but what this doctor is describing is fundamental to humane medicine.

\section{Lessons from the past}

Three episodes from the past, each of which has implications for the present day, illustrate the potential for inhumanity in clinical detachment.

\section{I: DRUGS BUDGETS}

To control the national drugs budget, Poor Law contracts of employment ruled that all medicines dispensed to the sick in workhouses were to be paid for out of the doctor's salary.

In the midsummer of 1872 Dr Joseph Rogers was appointed medical officer at the overcrowded Westminster workhouse. He was conducted around the building by a Mr French, who'd held the post for the previous forty years. In the course of this tour, Rogers discovered that the conditions inside 
the workhouse were atrocious, worse than anything described by Dickens, and Mr French laughingly confided the trade secret that he pocketed all his salary by means of the simple expedient of giving no physic. All patients - whether in mild, severe or even mortal pain-were prescribed coloured peppermint-water. ${ }^{2}$

The method of remuneration appealed to and benefited the worst motives of unscrupulous doctors-while penalising well motivated and benevolent ones. Rogers perceived it as doubly pernicious: corrupting and brutalising doctors, while exacerbating the suffering of patients in these huge old workhouse infirmaries, congested with sick and dying people.

So what do Mr French and Dr Rogers have to do with us? With the help of the Lancet, Rogers campaigned against the gross abuse of penalising workhouse doctors for prescribing proper treatment. The Poor Law administration was eventually shamed into establishing a system of capitation payment for salary, with a separate dedicated drugs budget. These remain the basis of remuneration for general practitioners in the National Health Service. $^{3}$

A recent report in Pulse, concerning balancing practice remuneration against prescribing costs, quoted a Chelmsford GP, Dr Anne Dyson:

"We have made as many savings as we can without cutting into patient care. The flesh was cut right back to the bone a long time ago. How can we be unbiased in prescribing when you know it might come out of your pocket?"

\section{II: PRESUMING UPON CONSENT}

Transplantation is often presented as a phenomenon of the twentieth century. In fact it's a development in the much longer history of surgery, and rooted in anatomical exploration. Looking back at that history, with a consciousness of the current shortage of organs for transplant, one cannot help but perceive that problems like those of the past are being played out afresh in our own time.

The surgeon-anatomist John Hunter (brother of William-he of the "Necessary Inhumanity") performed successful autotransplants on cockerels, moving the spur from a bird's heel to its own head, where it proliferated. It was only a short step to the practical application of such ideas to human subjects. In the $1770 \mathrm{~s}$, he recommended the transplantation of teeth, which was rapidly adopted by high-class dentists, first using teeth supplied by grave-robbery, then from living child "donors".

The exploitative nature of these operations was evident to contemporaries. The cartoonist Thomas Rowlandson vilified Hunter, and the novel, Adventures of a Rupee (1782) revealed the catastrophic long term effects on children already poor, of the removal of healthy second teeth: the dietary impact of being unable to masticate, and the permanent damage to facial appearance, resulting in the likely loss of a normal married or working life. ${ }^{6-7}$

The demise of the practice can be traced not to ethical questionability, but to clinical failure- decomposition of the tooth invariably followed after a time. In the Medical Transactions of The Royal College of Physicians in 1785, Sir William Watson reported a fatal case: syphilis had been transmitted to a recipient in an infected tooth. ${ }^{8}$ Hunter was apparently impervious to lay ethical criticism. He denied clinical failure, and cast doubt on stories of disease spread.

I've occasionally seen the cockerel mentioned as a progenitor of modern transplantation, and Hunter is often called the "Father of Modern Surgery", but the story of the teeth seems too often (and unaccountably) overlooked.

The problem of obtaining human materials has been largely resolved since the National Health Service. Donation supplies all UK dissection rooms, blood donors keep the blood banks going, and over eight million British citizens have currently registered themselves on the UK organ donor register, established less than a decade. Obtaining body parts by theft, purchase, coercion or trickery, as in the past, is quite unnecessary, and rightly perceived as unethical. Nevertheless the current policy of the British Medical Association is to promote "presumed consent", or, taking without asking.

\section{III: SPECIMEN TAKING}

By far the great majority of the human specimens in UK medical museums were obtained without consent.

The most spectacular specimen in the Royal College of Surgeons' Museum in London is the skeleton of Charles O'Brien, or Byrne, otherwise known as the Irish Giant, almost eight feet tall. In the 1780s he was a living human exhibit-rather like the Elephant Man. His fear of dissection was so intense that before his death in 1783 he had accumulated a large sum of money (said to be $f 500$ ) to have his body buried at sea in a lead coffin. His undertaker, however, was heavily bribed (apparently to the same amount) to deliver the corpse instead to John Hunter's dissection rooms. O'Brien's skeleton continues to serve as a monument to the morality of the medical museum, to theft, to medical acquisitiveness, and to a historic injustice. ${ }^{9}$

It was from the basement of this institution that the artist Anthony Noel Kelly took the body parts which recently landed him in jail for theft. The irony of his prosecution cannot be lost on anyone who contemplates the sources of the college's specimen collection. ${ }^{10}$

Pathology as a discipline-and its customary manner of specimen-taking, too-has preserved many of the attitudes of its forbears. Many hundreds, possibly thousands of parents in Bristol, Liverpool, Southampton, Leeds, London and elsewhere have suffered profound distress because their children's organs have been "retained" after postmortem examination (and in many cases disposed of) without consent. The attempt to maximise yield by deception has caused terrible anguish and damage to bereaved relatives, and has brought the entire medical profession into disrepute. ${ }^{11}$ 
I'm a rationalist. I have no problem with the idea that medical science needs body parts, that bodies need to be dissected, that students need to train, that surgeons need to understand fetal and other abnormalities, that postmortem findings are important. But I also believe that human beings have feelings, and it is the job of a caring profession to respect them. We all also have rights, and one of the most fundamental of human rights is the right to freedom of self determination.

An inhumane attitude of mind has pervaded medical dealings with a too trusting public. The attitude is inhumane because it denies our common humanity. I suspect it may derive from the fact that many doctors learn in the process of becoming doctors to deny aspects of their own humanity.

\section{The humane doctor}

As we've seen it's quite possible for doctors to behave inhumanely: Mr French laughed as he described the coloured water he'd meted out to the dying for forty years. John Hunter extracted healthy teeth from the mouths of poor children, and paid the undertaker to deny the Irish Giant his rightful burial.

These doctors were without pity, able to ignore, deny, overlook or even despise their patients humanity. Their motives were fundamentally acquisitive. Their activities thrived in closed institutions - the workhouse, the anatomy school. In each of these stories, too, government had a hand-failing to protect children, administering a heartless Poor Law, choosing neither to oversee nor adequately to regulate the conduct of the anatomy school, the dentist's surgery, the workhouse. Dissection rooms remain immune to public scrutiny, as do operating theatres, coroners' mortuaries, research laboratories and medical museums.

Each of these stories also has its humane professional, who nudged matters towards change-Dr Rogers, serving his workhouse patients even to the extent of losing his job; Sir William Watson, lifting the lid on a corrupt and highly lucrative surgical intervention by revealing its clinical dangers, and Dr Stephen Bolsin, who blew the whistle at Bristol. In each case, the humane doctor's moral intelligence has been more in touch with public opinion than has the inhumane.

\section{A Necessary Inhumanity?}

A "Necessary Inhumanity" is in my view greatly preferable to 'clinical objectivity' for describing the necessary distance from the patient which the trainee doctor must attain, in order to become a good clinician. It more honestly and precisely describes an aspect of the doctor/patient relationship. Were we to resurrect the phrase, to return consciously to using it, knowing what we know, and with the science we now have, it might become evident that clinical detachment is not a simple acquisition, but a spectrum of sensibility which can range from extreme cruelty to conscious empathy.

The notion of a "Necessary Inhumanity" could be valuable because the questions it prompts might help serve as an effective calibrator: how necessary in these circumstances? For how long? And with what effect? Resurrecting and knowingly reembracing the term "inhumanity" now might mean an increased awareness of its dangerous potential, which in turn might mean there'd be less of it about.

Ruth Richardson, D.Phil, FRHist Soc is a Historian and author of Death, Dissection and the Destitute (Chicago UP, 2000. In press) and Monkton Copeman Lecturer at the Society of Apothecaries. She is the author of many articles for such journals as the British Medical fournal, and the Lancet and she is a broadcaster of documentary history programmes for $B B C$ Radio 4 and the World Service.

\section{Acknowledgement}

The author thanks Brian Hurwitz and Deborah Kirklin for their constructive observations on this piece.

\section{References}

1 Hunter W. Introductory lecture to students [circa 1780]. St Thomas's Hospital Manuscript 55: 182. Dr Marion Bowman kindly ing my book Death, dissection and the destitute. Chicago: University of Chicago Press, new edition currently in press.

2 sity of Chicago Press, new edition currently in press. Rogers J. Reminiscences of a work

3 Richardson R, Hurwitz B. Dr Joseph Rogers and the reform of workhouse medicine. British Medical fournal 1989;509:150710.

4 Callaghan D, Ryan C. Ministers in $£ 114 \mathrm{~m}$ u-turn on GP drugs cash crisis. Pulse 2000 Jan 8: 60:1

5 Richardson R. Transplanting teeth: reflections on a cartoon by Thomas Rowlandson. Lancet 1999;354:1740.

6 Rowlandson T. Transplanting of teeth. London: W Holland, 1790. Prints and Drawings Department of the British Museum, London.

7 Anon [Scott H]. Adventures of a rupee. London: J Murray, 1782: 189-91.

8 Watson W. [Transmission of fatal venereal infection in a tooth transplant] read at the Royal College of Physicians, May 28th 2000. Watson's report was printed in the Medical transactions of the Royal College of Physicians. London: Royal College of Physithe Royal College of

9 Royal College of Surgeons of England. Descriptive catalogue of the pathological series of the Hunterian Museum [vol 1]. London: Royal College of Surgeons of England 1966: 190-2.

10 Wildgoose J. An acceptable body of work? Daily Telegraph 1998 May 9: Arts and Books section: A7. Wildgoose J. Catalogue essay for AN Kelly's exhibition, Birthdays. London: 291 Gallery, 1999.

11 Bristol Royal Infirmary Inquiry. Interim report: removal and retention of human material. Bristol: Bristol Royal Infirmary, May 2000. See also Richardson R. Tissue retention-an outsider's view. Bulletin of the Royal College of Pathologists, 2000 (in press). 


\section{Book reviews}

\section{Unhealthy Societies- the Afflictions of Inequality}

Richard Wilkinson, London, Routledge, 1996, xi +255 pages, $£ 17.99$ (sc).

Why read this book? Read it if you are interested-professionally or otherwisein the current state of society and the effects this has on our health. And in this case read it even if the complexities of epidemiological research, of anthropology, of social psychology, economics, history or politics are not your homeground: for though the book draws on all these areas it can and should be read from cover to cover.

Wilkinson's thesis concerns the relationship between relative income and mortality. He shows this relationship to hold very strongly within a given society or social grouping, ie it is the distribution of income rather than its absolute level which seems the more important, particularly so in developed countries. Wilkinson shows early on how relative deprivation becomes a major determinant of health once a society has passed through the socalled "epidemiological transition"where predominantly infectious causes of death give way to predominantly degenerative causes (cancer, cardiovascular disease, stroke etc), and where the stark relationship between lifeexpectancy and per capita income declines as absolute incomes rise. (Interestingly, this also seems to mark a change in the social distribution of some major diseases including most importantly coronary heart disease: in affluent societies the so-called "diseases of affluence" actually shift to the poor.)

Wilkinson then looks for possible explanations for those inequalities in health that are associated with living standards. Genetics, and anomalies of classification or measurement, are shown to contribute nothing; the effects of social mobility, medical care and individual health related behaviour provide only a partial influence. This leaves as the major influence the effects of the social and economic circumstances in which people live "Health ... gives us a handle of hard data on the subjective impact of experience ... [We] are discovering the toxicity of social circumstances and patterns of social organisation."

Wilkinson develops the case for regarding relative income as the more important factor, by re-examining existing data from a new conceptual standpoint, illustrated by neat historical case studies. He considers on the one hand societies experiencing a rapid compression of income distribution, accompanied by dramatic improvements in life-expectancy (as, twice, in wartime Britain); and on the other hand societies experiencing a rapid widening of income differentials, resulting in a breakdown of community cohesion and a sharp increase in deaths from coronary heart disease (as in the small close-knit Italian-American community of Roseto, Pennsylvania in the 1960s). The picture starts to emerge strongly: "inequalities are not an inescapable fact of modern life".

From here the author develops the concept of social cohesion. He draws on a wealth of anthropological literature, and on ideas from the field of social psychology, to establish the reality of this concept and, more significantly, its crucial role in human health. The huge themes this raises are worth some quotation: "[We] live in ways that are not conducive to social harmony because we are protected [by an overriding authority] from most of the social consequences of doing so ... only under [that authority's] jurisdiction can the complaints of the dispossessed be safely ignored. "[We] come to believe that human beings are by nature what their culture suggests they are ... [We] fail to realise how soon a different social order might come to seem a reflection of a different human nature."

The latter part of the book deals with the possible physical pathways involved. One of the most plausible is the role of chronic stress mediated through the hypothalamic-pituitaryadrenal axis linked to raised corticosteroids, central obesity, insulin resistance, poor lipid profile and increased blood-clotting-with evidence linking all this to the social ordering of the population.

The range and depth of this book do not lend it to compression, since it reads as a whole: it gathers weight and momentum and it strikes up major themes which seem to resonate and coalesce of their own volition, while maintaining an open and balanced feel. The merits of this book lie not only at the level of detailed content (which will inevitably date as research moves on). It can already be seen as a pivotal point in the direction of related research. Its methodology is attractive to the medical humanities, because it runs counter to the fashion for subdisciplines guarding ever-smaller areas of exclusive expertise, and because it deals with complex issues straddling several disciplines. The value of conceptual thinking is outstandingly demonstrated, as "evidence" takes on new meanings from different viewpoints. Moreover it refocuses attention on the subjective quality of life as crucial for assessments of social vitality, making material and economic aspects of secondary and indirect importance.

Finally the text is accessible, it assumes no specialist knowledge, and it manages to evoke genuine excitement at the "first views of the landscape ahead". Read on!

RICHARD EVANS

General Practitioner, Swansea, UK

\section{Clinical Judgement- Evidence in Practice}

R S Downie, Jane Macnaughton, Oxford, OUP, 2000, 212 pages, $£ 19.95$.

The authors define the aims of this book as being: (1) to make a case for the centrality and irreplaceability of clinical judgment; (2) to identify the elements of good clinical judgment, and (3) to suggest how these might be developed by using the humanities in medical education.

The book's message could be summarised as "evidence based practice is not enough". The case is made by looking at four elements of judgment. Science is not merely a question of facts but also of their interpretation and the construction of theories, matters of judgment. Clinical judgment is needed to apply the general principles of scientific medicine to the individual, who is never identical with the average patient. The two chapters which discuss these topics, although worthy, are 
in the traditional rather ponderous style of British philosophy, and might have least appeal for those who most need to read them.

The chapter on humane judgment is easier reading and more interesting, exploring the relationship between autonomy, consumerism and professional judgment. A brief chapter on judgment in public health is followed by perhaps the best chapter, a clear account of both the facts and values of rationing. This would be an excellent text to give on an introductory course on this important issue, and I have little doubt that I shall use it as such. The final chapter rehearses the arguments in favour of the medical humanities, which are likely to be well known to readers of this journal.

Paradoxically, perhaps because of my background in experimental psychology, I couldn't help feeling that many of the chapters could themselves have benefited from a bit more evidence-particularly those on clinical judgment and the benefits of teaching the humanities, where empirical research has as much to teach us as philosophy.

The book certainly makes the case for clinical judgment, although not always in a very accessible way. Whilst it includes some interesting insights into the nature of clinical judgment, and into the place of medical humanities in its development, I did not feel that the authors really achieved their second and third aims. As a whole I found it hard to see for whom the book was written. Those committed to the view that medicine is both a humanity and an art will find little new here, whilst those still locked in a positivist time-warp (and sadly there are still many such souls in purgatory) might find the style too discursive and philosophical to stick with it.

PETER TOON General practitioner, London, UK

\section{Just a Head: Stories in a Body}

Denise Fassett and M R Gallagher, Australia, Allen \& Unwin, 1998, 148 pages, $£ 12.99$

"I was no longer an academic, a runner, a skier or a traveller. Essentially I became just a head. My body was gone: I was no longer a physical being." This is how M R Gallagher, previously a diabetes researcher and triathlete from Tasmania, begins this account of her five-year experience of illness, cowritten with friend and nursing lecturer Denise Fassett. After an asthma attack and ten days in intensive care she found she was unable to move her arms and legs, had difficulty swallowing and continuing problems breathing. Tests did not reveal a cause and as she becomes more and more disabled, $M$ $\mathrm{R}$ finds herself in the "medical wilderness of the psychosomatic". There is no cure. Five years later she remains in a nursing home, wheelchair-bound, with poor vision and generalised pain. She is surrounded by and attached to the paraphernalia of disability: a catheter, a feeding tube, and a voiceactivated computer. The reader is ultimately left uncertain about whether there is a physical diagnosis. M R's experience of her illness has led her to campaign for her own and others' assisted suicide and she plans a $\mathrm{PhD}$ to explore the doctor-patient relationship.

At the heart of the book is M R's struggle for a physical diagnosis. Her faith in science, the hospital's apparent narrow-mindedness, her disembodiment through the experience of hospitalisation and lack of diagnosis become a potent barrier to recovery. When the doctors finally give up and she becomes a "psych consult", her condition deteriorates dramatically. She herself, her co-author, Fassett, and perhaps some of the hospital staff, equate this label with blame, stigma and a disease that is no longer "genuine". She is happy to receive psychotherapy and antidepressants for her depression but not to treat her physical symptoms.

Fassett is explicit in her aim as co-author to tell M R's story as an "ill person", using narrative as a "research technology", not to find out why she has become ill. In doing so she narrows the scope of the book but provides a rarely performed service of documenting the distressing situation in which patients with severe unexplained symptoms in a medicalised setting can find themselves. $M$ R's inability to obtain a label to legitimise her symptoms only seems to make her more ill and angry. Doctors, nurses and other professionals emerge murkily from the narrative. They are largely distant, unsympathetic figures who are portrayed emphasising $M$ R's objectification of her body.

At one point $\mathrm{M} \mathrm{R}$ reminds us of Smyth's adage: “ask not what disease the person has but what person has the disease". Paradoxically, this book, conceived as the story of a personal journey through illness, fails to answer this central question. Behind Fassett's insistent intellectualisation, I felt I learnt very little of M R's everyday life, her relationships, her family and her prior history. I was disappointed that the book didn't tackle some of the crucial issues. How can a person end up in such a disabled state if there is no apparent cause? Has the medical system colluded to make her ill? Would a label early in her disease have helped her to get better? Why does she think she will never get better? In M R's case, like many others, a complex mixture of organic disease, iatrogenesis, psychological, social and cultural factors are probably at work.

M R's story will be sadly familiar to anyone working in neurology, liaison psychiatry or rehabilitation medicine. She is one of the "undiagnosed": the most severe end of the spectrum of medically unexplained symptoms that make up one third of hospital outpatients and an even greater proportion of general practice work. Patients like M R are not rare-up to ten per cent of patients in young disabled units in the UK may fall into a similar category.

Health professionals often find patients like M R difficult to help. Discussing psychosocial factors that may be important in the genesis or maintenance of illness, and the performing of tests that are negative, can alienate patients, yet a failure to do so would be negligent. This dilemma, found every day in most medical practice, reflects the poor schemata and linguistics that we have for dealing with human somatic distress.

JON STONE

Research fellow in Neurology, Edinburgh, UK

\section{Correction}

In the December 2000 issue of Medical Humanities the following acknowledgements were inadvertently omitted: Barker P, Metaphors of life and death and Richardson R, A necessary inhumanity.

The original versions of the papers on which these articles are based were first presented at a conference, The Healing Arts: the Role of the Humanities in Medical Education, held at the Royal Society of Arts on 30th March 2000. The papers are reproduced in their original form, complete with illustrations, in D Kirklin and R Richardson, eds. Medical Humanities: an Introduction. London: Royal College of Physicians, 2001. 